\title{
'Absurd' Rationalist Cosmology: Copernicus, Kepler, Descartes and the Religious Basis for the end to Aristotelian Dogma
}

\author{
Nicholas Smit-Keding
}

Current popular narratives regarding the history of astronomy espouse the narrative of scientific development arising from clashes between observed phenomena and dogmatic religious scripture. Such narratives consider the development of our understandings of the cosmos as isolated episodes in ground-breaking, world-view shifting events, led by rational, objective and secular observers. As observation of astronomical development in the early 1600s shows, however, such a narrative is false. Developments by Johannes Kepler, for instance, followed earlier efforts by Nicholas Copernicus to refine Aristotelian-based dogma with observed phenomena. Kepler's efforts specifically were not meant to challenge official Church teachings, but offer a superior system to what was than available, based around theological justifications. Popular acceptance of a heliocentric model came not from Kepler's writings, but from the philosophical teachings of Rene Descartes. Through strictly mathematical and philosophical reasoning, Descartes not only rendered the Aristotelian model baseless in society, but also provided a cosmological understanding of the universe that centred our solar system within a vast expanse of other stars. The shift than, from the Aristotelian geocentric model to the heliocentric model, came not from clashes between theology and reason, but from negotiations between theology and observed phenomena.

Popular historical narratives discussing the development of science have often noted the 'revolutionary' ground-breaking moments in scientific effort; moments that result not only in ground-breaking discoveries, but incredible weltanschauung or world view changes. Within astronomy for instance, popular narratives have often surrounded the changed view from religiously dogmatic, totalitarian understandings of systems devised by Aristotle and Ptolemy, to an understanding not only of a heliocentric system, but an entire universe filled with billions of individual star systems. In Neal deGrasse Tyson's rebooted "Cosmos" series, for instance, Tyson presents Giordano Bruno as a thinker before his day. Bruno is shown as an inspired, objective theorist, who years before Galileo's discoveries, dared to challenge religious dogma by suggesting the infinity of the cosmos rather than the simplistic, Earth-centric universe Catholic officials taught. Tyson notes Bruno as a sort of 'martyr' for the early days of scientific reason, challenging oppressive religious, non-scientific philosophy. ${ }^{1}$ Similar narratives have been noted for other figures, such as Galileo and Copernicus. Such narratives generalize historical moments to consider historical 'clashes' between those who rely upon objective reason and those who rely on faith. This form of narrative also argues science as developing in specific, isolated episodes, at which different paradigms come to replace one another. As Michael Friedman in his

\footnotetext{
${ }^{1}$ Cosmos: A Space Time Odyssey: Standing Up in the Milky Way, directed by Brannon Braga (2014; Los Angeles, CA: Twentieth Century Fox Home Entertainment, 2014), Video. Bruno was of course, tried by the Catholic Church. However, Tyson emphasizes his 'scientific' qualities as being the reason for his immolation, and makes no reference to Bruno's other heretical considerations.
} 
criticism of Thomas Kuhn noted however, this form of history "is much too narrow.",

Instead, one can argue that development of cosmology, particularly in the early 1600s, was a negotiation of theological considerations over observed stellar phenomena. The narrative is not so much a replacement of 'absurd' religious dogma and natural philosophy in favour of rational, objective and observed theory, but rather philosophically-justified theory enabling further observation and study. Johannes Kepler's efforts, for example, saw him go through a variety of considerations on how the solar system existed. His later works, such as the influential Astronomia Nova, used observations made, but also made use of religious justification and mysticism. Unlike Nicholas Copernicus, Kepler's system won greater appeal than simply an exercise useful for saving the appearances of the Aristotelian system. ${ }^{3}$ Similarly, Rene Descartes' Cartesian Universe expanded understanding to now consider a greater universe of immense proportions. Although this effectively brought an end to the Aristotelian consideration of a universe of concentric spheres, Descartes was not an astronomer, and his theory primarily used geometry and considerable theological justification. Nevertheless, Descartes' methods effectively redefined cosmology to considering the universe not as a finite, limited expanse, but as a massive, multi-solar existence. The line between refuting Aristotle's claim of a geocentric universe, to the consideration that the solar system was just one of many star systems was not a clear-cut narrative of secular science and scientists triumphing over the totalitarian nature of Church dogma, as would be suggested by Tyson's portrayal. Rather, it was a negotiation between various philosophical and theological considerations on observed phenomena.

As noted by Michael Friedman, Copernicus did provide a simpler and more harmonious system than the well-lived Aristotelian system; the basic philosophic elements behind it however, just could not branch out from the utilitarian advantages it provided. ${ }^{4}$ Copernicus' system arose from a common anxiety facing astronomer's using Aristotle's work. While official religious dogma of the time premised the superiority of Aristotle's design, the difficulties associated with retrograde motion meant that Ptolemy's epicycle system was needed for actual work. ${ }^{5}$ Aristotle's model made practical sense, yet Ptolemy had essentially arrived at a usable model based on his own observations. As Copernicus noted though, Ptolemy had created a system which was "not adequate unless certain equants were also conceived; it then appeared that a planet moved with uniform velocity neither on its deferent nor about the center of its epicycle." ${ }^{\prime 6}$ Copernicus hence saw his efforts not so much as an attack of traditional Church scripture

\footnotetext{
2 Michael Friedman, “A Post-Kuhnian Approach to the History and Philosophy of Science,” The Monist 93, no. 4 (2010): 497. Kuhn articulated scientific development as episodic, shifting between different understandings through specific moments in which paradigms would radically change.

3 The term Saving the Appearances refers to a practice in astronomical observation during 1500s. Period astronomers would provide mathematical understandings for stellar phenomena, but would regard the inability to position such theories within a heliocentric model as representative of the Aristotelian system's divinity. Mathematical models could provide understanding for stellar movement, but were separate from theological understanding and were not meant to specifically articulate astronomical movement as it was considered non-physical in nature.

4 Friedman, 505.

5 Though the Aristotelian model premised a geocentric notion of the universe, whereby the Earth was surrounded by concentric spheres responsible for stellar movement, the model failed to explain the occasional retrograde motion of the planets as seen by terrestrial observers. Ptolemy, a $2^{\text {nd }}$ Century Greek Mathematician, modified the system by placing the planets within a second circle of orbit - an epicycle - while still moving along the primary sphere of orbit. Though complex, the model did at least offer astronomers a capacity to predict the future positions of planets within the night sky.

${ }^{6}$ Nicolaus Copernicus, Three Copernican treatises: the Commentariolus of Copernicus, the Letter against Werner, the
} 
in nature, but rather as a needed refinement of an already problematic series of systems used in official services. In this role, Copernicus' simpler system may have been advantageous, yet it likely was a mistake that the Copernican system even got the recognition it did. ${ }^{7}$ Copernicus' system was less complex, but no more reliable than Ptolemy's. ${ }^{8}$ Additionally, the strictly theoretical structure Copernicus used in his writing, and the addition made by Andreas Osiander in De Revolutionibus orbium coelestium meant that Copernicus' 'paradigm shift' was muted. ${ }^{9}$ The revised system remained a theoretical consideration, which although useful, was not substantial enough to radically change popular discourse.

Kepler's own initial reaction to the Copernican system was nothing fundamentally ground-breaking, yet such a response was minor given Kepler's later successes philosophically and astronomically. Kepler, like other theologians of his day in, viewed the Copernican system as purely theoretical, though being this at the beginning of his career, he arrived at such a conclusion by strictly using Lutheran theology. ${ }^{10}$ Kepler's theological experience at Tubingen brought him into contact with a variety of different theories presented by scholars, with a set determination to settle natural observations and natural philosophy into one universal understanding. ${ }^{11}$ Indeed, while Kepler could criticize the Copernican system initially, Kepler nonetheless was engaging within a discourse that desired to re-evaluate astronomical theory to a working system that was in line with what could be seen in scripture. His move from Tubingen brought Kepler outside of traditional academia, yet his move hardly freed him from any theological perspective. Rather, Kepler's writings in 1596 still contended that any reassessment of an astronomical system still required the acknowledgement of God's intervention. Kepler noted, for instance, that for his own theoretical construction of the universe, divine intervention was the reason for why the universe existed at all. ${ }^{12} \mathrm{He}$ attempted experimentation with multiple geometric shapes in order to arrive at a workable system, yet his use of a geo-heliocentric model arose largely from the failures of other theories initially suggested as forms of a posteriori argument. ${ }^{13}$ Kepler contended that his geo-heliocentric model remained the only model that fit. Unlike Copernicus, his theory was a priori, non-theoretical argument precisely because it concluded that the unique, perfect mathematical nature could only come from a

Narratio prima of Rheticus (New York: Octagon Books, 1971), 57.

7 Friedman, 505. Friedman notes the possible mistake made in making Copernicus' system the centre of the new Gregorian Calendar. Had this not occurred, recognition of the Copernican model might have not even happened.

8 Ibid., 505.

${ }^{9}$ Osiander is notable for adding an introduction to Copernicus' De Revolutionibus, which specifically noted that Copernicus was in no way suggesting a heliocentric model of the universe as factual reality.

10 Peter Barker and Bernard R. Goldstein, “Theological Foundations of Kepler's Astronomy,” Osiris 2 $2^{\text {nd }}$ Ser, 16 (2001): 93.

11 Ibid., 96-97. Barker and Goldstein cite, for example, Philipp Melancthon's discourse, and the presence it had with Kepler's professors, mainly Michael Maestlin and Jacob Heerbrand.

12 Ibid., 99.

13 Ibid., 101. A Posteriori argument refers to the dominant logical technique of Kepler's time, the regressus. The approach was divided into three layers, the first being the Posteriori, which went through the process of saving the appearances in order to construct several hypotheses. The second layer, the negotiatio, appealed to known information in order to filter out alternative theories and derive a singular explanation for the phenomena. The final component, the $a$ priori, deduced how the discovered theoretical cause resulted in the effect. As Barker and Goldstein note, the priori argument relied heavily upon presumptions of the universe, such as the shape of the planet, or in the case of Kepler, the basic existence of God in all things. 
divine creator. ${ }^{14}$ In this respect, Kepler was not really suggesting anything new to Church dogma; rather he was arguing that the universe had to be along this geo-heliocentric model because the precise geometric nature was evidence of literally God's image in a perfectly constructed universe. ${ }^{15}$ Kepler was not necessarily suggesting that Copernicus was right; rather he advanced a further theory that effectively reaffirmed divine philosophy.

Kepler's later work differed substantially from his initial philosophic articulations. Yet, at the heart of his studies lay a reliance upon philosophical and religious justification, and it was this which was part and parcel to Kepler erasing any notion of physical structure causing the orbit of the planets. Kepler's New Astronomy in 1609, for instance, re-evaluates his earlier consideration of the planets in fixed spherical physical bodies. His original consideration likened the arrangement of the planets to the harmonious construction God embedded in nature. However, as Peter Barker and Bernard Goldstein argue, Kepler never specifically argued the fixture of planets in a physical sense, as a priori argument; rather their geometric arrangement was the priori. ${ }^{16}$ To some respect, this was true; Kepler published his initial claims in 1596 with stronger reliance upon mathematical principles rather than astronomical observation. His later interactions with Tycho Brahe and own observations though challenged some considerations Kepler had made as priori, such as the geometrical arrangement of the orbits, and the centrality of this as being evidence of divine support. Kepler did have to revise his system quite substantially because of this, entirely abandoning any consideration for a geometric arrangement particularly after his 'campaign' against Mars. ${ }^{17}$ His system now integrated the Sun as being the direct cause for the orbits of the planets, and the notion that the planets circled in elliptic, magnetic orbits. From this, Kepler articulated two of the three laws of planetary motion. His effort in this regard however, did not dismiss any of the earlier religious dogma. Indeed, as Barker and Goldstein argue, Kepler's specific cause for articulating a physical law emerged from the astrological, Lutheran teachings of Philipp Melancthon. Melanchthon, for Barker and Goldstein, took to an Aristotelian methodology of exemplum, misinterpreting it as a tool used for inferring a universal constant or rule. ${ }^{18}$ For Melanchthon and later Kepler, as is suggested, exemplum is a means to infer rulings descending from God, that define how the universe works. ${ }^{19}$ In this sense, Kepler was not so much inferring an objective rule, but was articulating that by evidence of this specific limitation of motion, God had to exist.

There is a certain amount of evidence to support Barker and Goldstein's thesis. Kepler sometime after 1605, according to Max Casper, noted his goal not as a mission to prove the universe as a divine being, but rather as a "heavenly machine" in "so far as almost all the manifold motions are taken care of by

\footnotetext{
${ }^{14}$ Ibid., 101.

15 Ibid., 103.

16 Ibid., 103. Kepler, in this fashion, suggested that the harmony of the static structure of the universe mirrored the Holy Trinity of God. Simply put, Kepler believed that the Priori was essentially the image of God found within the basic construction of the universe.

17 Michael Hoskins, The Cambridge Concise History of Astronomy (Cambridge: Cambridge University Press, 1999), 107108. As Hoskins elaborates, Kepler entered into a protracted effort to track the Martian orbit from his and Tycho Brahe's observations. He characterized this as his own personal 'war' with Mars, whereby the observations he made forced a significant rethink in his earlier geometric models.

18 Barker and Goldstein, 104.

19 Ibid., 104.
} 
one single absolutely simple magnetic bodily force." 20 To a certain extent, this is almost the same statement made by Kepler in 1596 in The Sacred Mystery of the Cosmos, in which Kepler argues that the geometric nature of the universe is evidence of God's divine engineering. As Kepler puts it, his viewing is of "the sun, the fixed stars, and the intervening medium with God the Father, the Son, and the Holy Spirit." ${ }^{21}$ Both statements essentially suggest that Kepler's chief aim was in trying to see God, or evidence of God, within the universe. His observed world view never cast doubt over considerations of a divinely made structure; rather Kepler started his processes with unyielding faith in God and a need to construct, almost as with Copernicus, a system which could harmoniously explain theology and the universe. $^{22}$ Regardless of whether his system was initially finite and limited to a geo-heliocentric universe, or whether it was elliptical, expanded, and sun-centered, Kepler's theology was intrinsic to his continued expansion of the cosmological understanding

Kepler was not alone in challenging Aristotle's limited system within an expanse of theological philosophy. Indeed, only three years after Kepler died in 1630, Rene Descartes was already in the process of articulating a theory of motion based around a heliocentric model similar to Copernicus' system. $^{23}$ The result came in 1644 with the publication of Principia Philosophiae, which although being primarily based around Descartes conception of motion, the publication effectively brought the concept of an expanded, heliocentric universe to popular discourse. This happened primarily through Descartes' articulation of motion; while Copernicus and Galileo could not explain the physical processes that resulted in the motion of planets around the sun, Descartes came at the issue relying upon his consideration of God's immutability. Descartes explained that motion occurred due to divine intervention; at the beginning of the universe, God had endowed existence as a persistent matter filled reality. ${ }^{24}$ Motion, in this sense, is the result of creation, and is the result primarily of matter throughout the universe interacting with itself. ${ }^{25}$ Any disturbance, according to Descartes, causes vortexes to occur, which in the case of the Copernican solar system, is the reason why the sun and the planets exist, and why the planets rotate around the sun. ${ }^{26}$

Descartes, in this way, had accomplished an incredible academic feat. Not only did his publication effectively lead to the destruction of the Aristotelian system as accepted belief, but he had also expanded cosmological considerations of the universe to consider now a massive expanse filled with various heliocentric star systems, all while relying upon logic, religious dogma and math. As Rienk Vermij argues, "it was Cartesianism which turned the heliocentric theory into an acceptable and indeed dominant theory." 27 This statement indeed has credibility, as Descartes' chief advantage was the logical

\footnotetext{
${ }^{20}$ Max Casper, Kepler (Toronto: General Printing Press, 1993), 136. Casper does not note when exactly Kepler made this statement.

21 Barker and Goldstein, 103.

${ }^{22}$ Casper, 377. Casper points out how Kepler wanted to create "the Forma Mundi as harmony", or rather the basis by which the principles of order and configuration govern the cosmos.

23 Richard J. Blackwell, "Descartes' Laws of Motion," Isis 57, no. 2 (1966): 220. It should be noted though that according to Hoskins, Descartes likely was working in ignorance of Kepler's work. ${ }^{24}$ Ibid., 223.

25 Rienk Vermij, The Reception of the New Astronomy in the Dutch Republic, 1575-1750 (Amsterdam, Royal Netherlands Academy of Arts and Sciences, 2002), 140. 26 Ibid., 140.

27 Ibid., 140.
} 
and theological argument that sought explanation for the physical makeup of the cosmos in defining how they are structured. Descartes' position was successful as it formulated, like Kepler's theory, a central logical structure on how motion existed, and then noted the theological basis for why it existed. Conservation of motion existed, for example, due to the immutability of God's creation. ${ }^{28}$ Since no body could remain in motion, as the immutability of God abhors a vacuum, the whole of the universe must be 'something' from which motion can be continuously transmitted and felt. Motion than defines not only why stellar phenomena exist, but how they can work within a heliocentric model. Not only then could the Cartesian system rival the Aristotelian system, but it could do so without having to rely upon a Ptolemaic system for actual mathematical work. Individuals now had a system which did not require the discrediting of the very processes that made it useful in society, as with the Aristotelian/Ptolemaic relationship.

The narrative of cosmological development in the early 1600s was not consideration of the objective and rational triumphing over the religious, backwards and absurd. Rather, religious and nonastronomical arguments were central in how Western European academia came to accepting the thought that not only was the universe not centred around the Earth, but that the universe contained a great expanse of similar, sun-like stars. While the Copernican system may appear in hindsight to be a tremendous, revolutionary idea that heralded the forthcoming Cosmological 'revolution', such a narrative forgets the largely theoretical and unsubstantiated nature Copernicus' theory was presented and received in. It was for this reason, that when Kepler first interacted with the Copernican system in 1596 as a student, he fell in line with the rest of academia of his time and saw the system only for the value of saving the appearances. His own articulations of a heliocentric system came not from strictly secular, objective reasoning, but a profound devotion to faith, which pushed him to seek a more harmonious and workable theory than what existed at the time. The reason for why his theory and his 'laws' are remembered today was not the result of scientific articulation, but a belief that the inherent structure in the universe determined divine existence. The further development which finally ended the Aristotelian system did not come from astronomy itself, but rather the theological and philosophical teachings of Descartes. It was this Protestant Calvinist philosopher who was needed not only to render Aristotle's theory baseless, but expand Cosmological understanding far beyond what had previously been imagined. While some narratives may continue to offer up scientific 'martyrs' as examples of objective study 'butting heads' with dogmatic religion, such narratives remain stuck contending scientific development in a limited light. Indeed, during the early 1600s, developments in Cosmology were not great clashes between the ignorant and the informed, but negotiations of theory from scripture.

28 Blackwell, 223-224. 
Bibliography

Cosmos: A Space Time Odyssey: Standing Up in the Milky Way. Directed by Brannon Braga. Los Angeles, CA: Twentieth Century Fox Home Entertainment, 2014. Video.

Barker, Peter, and Bernard R. Goldstein. "Theological Foundations of Kepler's Astronomy." Osiris $2^{\text {nd }}$ Ser, 16 (2001): 88-113.

Blackwell, Richard J.. “Descartes' Laws of Motion.” Isis 57 no. 2 (1966): 220-234.

Casper, Max. Kepler. Toronto: General Printing Press, 1993.

Copernicus, Nicolaus. Three Copernican treatises: the Commentariolus of Copernicus, the Letter against Werner, the Narratio prima of Rheticus. New York: Octagon Books, 1971.

Friedman, Michael. "A Post-Kuhnian Approach to the History and Philosophy of Science.” The Monist 93, no. 4 (2010): 497-517.

Hoskins, Michael. The Cambridge Concise History of Astronomy. Cambridge: Cambridge University Press, 1999.

Vermij, Rienk. The Reception of the New Astronomy in the Dutch Republic, 1575-1750. Amsterdam: Royal Netherlands Academy of Arts and Sciences, 2002. 